\title{
Multi-criteria assessment of offshore wind turbine support structures
}

\author{
E. Lozano-Minguez ${ }^{\mathrm{a},{ }^{*}, \text { A. J. Kolios }}{ }^{\text {a }}$, F. P. Brennan ${ }^{\mathrm{b}}$ \\ ${ }^{a}$ Department of Offshore, Process \& Energy Engineering, Room 137, Whittle \\ Building (B52), Cranfield University, United Kingdom, MK43 0AL. \\ ${ }^{\mathrm{b}}$ Department of Offshore, Process \& Energy Engineering, Room 124, Whittle \\ Building (B52), Cranfield University, United Kingdom, MK43 0AL. \\ *Corresponding author. Tel.: +44 1234756162; Mob.: +44 7907774965 \\ E-mail address: e.lozanominguez@cranfield.ac.uk, estivaliz@ hotmail.com (E. \\ Lozano-Minguez)
}

\begin{abstract}
Wind power, especially offshore, is considered one of the most promising sources of 'clean' energy towards meeting the EU and UK targets for 2020 and 2050. Deployment of wind turbines in constantly increasing water depths has raised the issue of the appropriate selection of the most suitable support structures' options. Based on experience and technology from the offshore oil and gas industry, several different configurations have been proposed for different operational conditions. This paper presents a methodology for the systematic assessment of the selection of the most preferable, among the different configurations, support structures for offshore wind turbines, taking into consideration several attributes through the widely used multi-criteria decision making method TOPSIS (Technique for Order Preference by Similarity to Ideal Solution) for the benchmarking of those candidate options. An application comparing a monopile, a tripod and a jacket, for a reference 5.5 MW wind turbine and a reference depth of $40 \mathrm{~m}$, considering multiple engineering, economical and environmental attributes, will illustrate the effectiveness of the proposed methodology.
\end{abstract}

\section{KEYWORDS}

TOPSIS method, Multi-criteria decision making, Jacket, Monopile, Tripod offshore support structure, Offshore wind turbines 


\section{INTRODUCTION}

Wind energy has been used from ancient times, initially transforming wind energy into mechanical work for operating windmills and wind pumps, and later employed to generate electricity. From the first application of wind turbines at the end of the $19^{\text {th }}$ century [1], the world's first onshore wind turbine was installed in 1980 [2], standing as the vanguard for the significant development which followed in the field. The UK's first commercial wind farm was built in 1991 at Delabole [3], with a total capacity of 4 MW, establishing wind energy as a safe, clean source of energy on the UK's energy map.

Further developments in research throughout Europe, has moved interest in wind energy offshore [4], taking advantage of the unrestricted space, lower social impact and higher wind resource conditions [5]. In [6], it is estimated that an additional $50 \%$ of electricity can be generated by the same turbine in an offshore wind environment, compared to onshore. Although, the UK became involved later than other European countries in the research and testing of offshore wind turbines, starting with the Blyth wind farm [7], it is currently the leader in this sector with $1 \mathrm{GW}$ of offshore wind farms [8], overtaking Denmark in 2008 [9] and representing $44 \%$ of Europe's total installed capacity. Although transferring wind energy technology offshore presents several benefits, it faces the constraints of high construction cost, especially foundation and electrical connection with the shore, and limitations in operation and maintenance caused by limited access [1]. The depletion of fossil fuel reserves, the various crises of fossil fuel prices and its great contribution to climate change have forced several countries in the EU to turn towards alternative forms of sustainable energy. In 2007, European leaders agreed that the EU will reach a $20 \%$ share of energy from renewable sources by 2020, by setting individual targets for all Member States [10]. The UK aims to obtain $15 \%$ of its final energy consumption from renewable sources by 2020 and to cut $\mathrm{CO}_{2}$ emissions by a minimum of $26 \%$ by 2020 and $60 \%$ by 2050 [11], having the best geographically varied wind resources in Europe [12]. In order for those targets to be achieved, it is an essential requirement to make this industry more economically efficient through the optimization of components such as offshore wind turbine support structures. This paper aims to provide an analytical methodology for the selection of the most preferable from the three most commonly used support structure configurations - monopile, tripod and jacket - 
for a typical 5.5 MW wind turbine in $40 \mathrm{~m}$ water depth. In this analysis;

engineering, economics and environmental assessment will be considered in order to balance the socio-economic activities of the sustainable energy sector [13]. The widely used multi criteria decision making method TOPSIS (Technique for Order Preference by Similarity to Ideal Solution) will be applied, allowing consideration of both quantitative and qualitative criteria, in order to incorporate multiple attributes into the decision making process.

\section{DESIGN AND OPTIMIZATION OF WIND TURBINE SUPPORT STRUCTURES}

Within the scope of this study, the three most common configurations of offshore support structures were studied [14]:

- Monopile is a simple design, the foundation of which consists of a tubular structure that extends into the seabed; it is used for installations at water depths of up to $25 \mathrm{~m}$.

- Tripod is three-legged structure made of cylindrical steel tubes, and is used for installations at water depths between 25 and $50 \mathrm{~m}$.

- Jacket is a (usually) four-legged structure made of cylindrical steel tubes and, as with the tripod, is used for installations at water depths between 25 and 50 m.

Figure 1 presents a conceptual illustration of the different configurations.

The design of offshore structures is based on a combination of the Finite Element Method (FEM) and the provisions of design standards such as [15] and [16]. The methodology that is followed involves the construction of an initial finite element model of the structure, which takes into account the soil structure interaction and the loads acting on the structure in two different case studies - maximum operation and survival conditions. The basis for the design is selected as Eurocode 3 for quasi-static analysis, generating a global safety factor based on its provisions for load combinations and material properties. Design optimization took place through an iterative process in order to efficiently utilize material properties. For the design of all three cases, the same tower was considered based on [17]; 90 $\mathrm{m}$ length, $6 \mathrm{~m}$ base diameter and $0.02 \mathrm{~m}$ thickness, and $3.87 \mathrm{~m}$ top diameter and 
$0.02 \mathrm{~m}$ thickness. Tables 1 to 3 present the material, soil and environmental properties that have been considered for a hypothetical site of deployment.

\begin{tabular}{ll}
\hline Young's modulus (E) & $210 \mathrm{GPa}$ \\
Shear modulus $(\mathbf{G})$ & $80.8 \mathrm{GPa}$ \\
Density $(\boldsymbol{\rho})$ & $8,500 \mathrm{~kg} / \mathrm{m}^{3}$ \\
Yield Stress $\left(\mathbf{s}_{\mathbf{y}}\right)$ & $355 \mathrm{MPa}$ \\
Poisson's coefficient $(\mathbf{v})$ & 0.3 \\
\hline
\end{tabular}

Table 1: Material Properties

\begin{tabular}{ll}
\hline Submerged Dense Sand & \\
\hline Young's modulus $(\mathbf{E})$ & $75 \mathrm{MPa}$ \\
Poisson's coefficient $(\mathbf{v})$ & 0.3 \\
Horizontal subgrade reaction $\left(\mathbf{n}_{\mathbf{h}}\right)$ & $10 \mathrm{MN} / \mathrm{m}^{3}$ \\
\hline \multicolumn{2}{c}{ Table 2: Soil Characteristics }
\end{tabular}

\begin{tabular}{lll}
\hline & $\begin{array}{l}\text { Case 1: Extreme } \\
\text { wind conditions }\end{array}$ & $\begin{array}{l}\text { Case 2: Operating } \\
\text { conditions }\end{array}$ \\
\hline Wave height $(\mathbf{H})$ & $10.6 \mathrm{~m}$ & $10.6 \mathrm{~m}$ \\
Wave period $(\mathbf{T})$ & $9.6 \mathrm{~s}$ & $9.6 \mathrm{~s}$ \\
Wind velocity at $\mathbf{1 0} \mathbf{m}$ above the sea level $\left[\mathbf{W}_{\mathbf{1 0}}\right]$ & $8 \mathrm{~m} / \mathrm{s}$ & $8 \mathrm{~m} / \mathrm{s}$ \\
Gust wind speed at $\mathbf{1 0} \mathbf{m}$ above Standing Water Level $\left[\mathbf{U}_{\mathbf{G}}(\mathbf{1 0})\right]$ & $35 \mathrm{~m} / \mathrm{s}$ & $12 \mathrm{~m} / \mathrm{s}$ \\
Aerodynamic Loads & No & Yes \\
\hline
\end{tabular}

Table 3: Environmental Conditions

The structural models have been built with the Abaqus/CAE, which is a powerful engineering software tool based on the FEM. After several iterations, dimensions of structural members were optimized; the results for each case are presented in Tables 4 to 6 . Table 7 presents the maximum displacement and maximum von Mises stress to which the different support structures are subjected.

\begin{tabular}{llll}
\hline & Length $(\mathbf{m})$ & Diameter $(\mathbf{m})$ & Thickness $(\mathbf{m})$ \\
\hline Tower Top & 87.6 & 4.1 & 0.013 \\
Tower Base & 87.6 & 6 & 0.021 \\
Transition Piece & 10 & 7 & 0.04 \\
Pile & $35+40$ & 7 & 0.04 \\
\hline
\end{tabular}

Table 4: Optimized Monopile Design 


\begin{tabular}{llll}
\hline & Length $(\mathbf{m})$ & Diameter $(\mathbf{m})$ & Thickness $(\mathbf{m})$ \\
\hline Transition piece & 10 & 8 & 0.4 \\
Central Column & 35 & 8 & $0.04-0.08$ \\
Braces & 36.06 & 4.1 & 0.026 \\
Base & $20-34.64$ & 2.1 & 0.016 \\
Piles & 35 & 3.6 & 0.04 \\
\hline
\end{tabular}

Table 5: Optimized Tripod Design

\begin{tabular}{llll}
\hline & Length $(\mathbf{m})$ & Diameter $(\mathbf{m})$ & Thickness $(\mathbf{m})$ \\
\hline Tower & 87.6 & $5.1-7.02$ & $0.02-0.028$ \\
Braces Hor. 1 & $16.4-24.8$ & 2.1 & 0.016 \\
Brace Diagonal 1 & $22.69-27.30$ & 2.1 & 0.016 \\
Braces Hor. Long 1 & $23.19-42.42$ & 2.1 & 0.016 \\
Piles & 33.3 & 5 & 0.04 \\
\hline
\end{tabular}

Table 6: Optimized Jacket Design

\begin{tabular}{lll}
\hline & Maximum displacement & Maximum von Mises Stress \\
\hline Monopile & $2.37 \mathrm{~m}$ & $177.6 \mathrm{MPa}$ \\
Tripod & $3.30 \mathrm{~m}$ & $184 \mathrm{MPa}$ \\
Jacket & $2.69 \mathrm{~m}$ & $223.8 \mathrm{MPa}$ \\
\hline
\end{tabular}

Table 7: Maximum Displacement and von Mises Stresses

\section{DESIGN ATTRIBUTES}

In the previous section, the design of the support structures was discussed and the maximum displacement and von Mises stresses were derived. This section will consider multiple attributes regarding environmental and economical assessments of the different configurations.

\subsection{Environmental Impact Assessment}

The assessment of the possible impact, negative or positive, that a project or a policy might have on the environment is known as environmental impact assessment (EIA). The European directive on EIA, which was transformed into a legal obligation among European countries, requires an EIA study for offshore structures as part of the licensing process [18]. Offshore wind farms have both harmful and beneficial environmental consequences for the marine environment. The main negative effects are: impact on birds, underwater noise and vibration, water turbidity, and electromagnetic interference. The main positive effect is that 
the foundations may act as artificial reefs. The degree of impact on biodiversity and ecosystem functions will depend on the chosen location [19]. The aforementioned are local impacts, whereas the global impact can be identified by distinguishing the fabrication process of wind turbines and support structures as negative impacts, whereas the low carbon emissions over the turbine's lifecycle, as well as negligible emissions of nitrous oxides, mercury and sulphur oxides, relative to conventional sources of energy are regarded as positive global impacts [20]. In this section some of the most important impacts will be presented.

\subsubsection{Carbon Footprint}

There seems to be some confusion about the definition of carbon footprint [21]; the spectrum of definitions ranges from direct $\mathrm{CO}_{2}$ emissions to full life-cycle greenhouse gas emissions, with different considerations of units of measurement. For this analysis, only $\mathrm{CO}_{2}$ emissions related to the production of steel from extraction, transportation, processing, manufacturing and construction will be considered. The amount of $\mathrm{CO}_{2}$ equivalent $\left(\mathrm{CO}_{2} \mathrm{e}\right)$ emissions per $\mathrm{kg}$ of steel produced will be calculated by the emissions of $\mathrm{N}_{2} \mathrm{O}, \mathrm{CH}_{4}$ and $\mathrm{CO}$ by the following empirical formula [22]:

$$
\mathrm{CO}_{2} \mathrm{e}=270 * \mathrm{~N}_{2} \mathrm{O}+24.5 * \mathrm{CH}_{4}+1.4 * \mathrm{CO}
$$

For steel members, the unit emissions per each $\mathrm{kg}$ of production for $\mathrm{N}_{2} \mathrm{O}, \mathrm{CH}_{4}$ and $\mathrm{CO}$ are correspondingly $0.07,0.04$ and $0.93 \mathrm{~g}$. Based on the results of the analysis given in Section 2, and taking into consideration the derived masses, Table 8 summarizes the emissions of each different configuration, illustrating that the jacket structure configuration has the greatest amount of $\mathrm{CO}_{2} \mathrm{e}$ emissions.

\begin{tabular}{llllll}
\hline & Mass of steel $(\mathbf{k g})$ & $\mathbf{N}_{\mathbf{2}} \mathbf{O}(\mathbf{k g})$ & $\mathbf{C H}_{\mathbf{4}}(\mathbf{k g})$ & $\mathbf{C O}(\mathbf{k g})$ & $\mathbf{C O}_{\mathbf{2}} \mathbf{e}(\mathbf{k g})$ \\
\hline Monopile & 811565 & 57 & 32 & 755 & $\mathbf{1 7 1 9 1}$ \\
Tripod & 1689552 & 118 & 68 & 1571 & $\mathbf{3 5 7 8 8}$ \\
Jacket & 2447038 & 171 & 98 & 2276 & $\mathbf{5 1 8 3 3}$
\end{tabular}

Table 8: $\mathrm{CO}_{2}$ emissions for different support structures

\subsubsection{Noise and Vibration}

Wind turbines can produce infrasonic vibrations which derive from the complex interaction of mechanical factors associated with machinery, rotation bearings, effects of wind, etc. In several cases it may be found impossible to predict them or their effect on the natural environment [23]. There are plenty of sources of 
underwater noise including wind farm related geophysical surveys, pile driving, foundation installation, drilling, cable trenching, rock laying, wind turbine operation, vessels and machinery, turbine structure installation, decommissioning, etc [24]. There is no identified potential for an adverse noise impact during the operational phase of the offshore wind farm [25].

Measurements of underwater noise, such as the studies of the sea mammals of the Bockstigen and Tuno Knob wind farms, off Sweden and Denmark respectively, have shown that offshore wind farms do not have a major impact on marine mammals [1]. During pile driving operations, the number of sea mammals decreases, but following the construction period they return although in lower numbers than before [20].

As the machinery used is the same and the duration of the work will not vary significantly, it can be assumed that the choice of foundation will not affect the impact.

\subsubsection{Water turbidity}

Installation and decommissioning of the foundations and cabling will result in considerable disturbance of the seabed, resulting in the removal or physical disruption of benthic communities and suspension of sediment. However, it is expected that the amount of deposited material is not enough to affect the morphology of the seabed [37]. For this study, it will be assumed that the environmental impact is proportional to the soil volume affected by the piles, as presented in Table 9, illustrating that the jacket type of configuration would produce more water turbidity.

\begin{tabular}{llllll}
\hline & Number of piles Length $(\mathbf{m})$ & Length $(\mathbf{m})$ & Radius $(\mathbf{m})$ & Area $\left(\mathbf{m}^{2}\right)$ & Volume $\left(\mathbf{m}^{3}\right)$ \\
\hline Monopile & 1 & 40 & 3.5 & 38.5 & $\mathbf{1 5 3 9 . 4}$ \\
Tripod & 3 & 35 & 1.8 & 10.2 & $\mathbf{1 0 6 8 . 8}$ \\
Jacket & 4 & 30 & 2.5 & 19.6 & $\mathbf{2 3 5 6 . 2}$ \\
\hline
\end{tabular}

Table 9: Affected soil volume

\subsubsection{Artificial Reefs}

Wind farm structures and any scour protection provide additional substrata for colonization by epifaunal communities, potentially increasing the biodiversity of the locality [25], although the benthic community may be modified as a result. For this study, it will be assumed that this environmental benefit is proportional to the 
total surface of each structural option, as presented in Table 10, according to which the monopile structure would produce the lowest increase in biodiversity.

\begin{tabular}{llll}
\hline & Monopile & Tripod & Jacket \\
\hline Total surface $\left(\mathbf{m}^{2}\right)$ & 1100 & 3857 & 8787 \\
\hline
\end{tabular}

Table 10: Total surface of each structural option

\subsubsection{Electromagnetic Fields}

Many fish species within UK waters are sensitive to magnetic and electric fields which can be caused by buried underwater cables. Fish use their perception of magnetic and electric fields for orientation and prey detection [20]. However, it is not yet known whether the fish will suffer any consequences caused by this interaction [26]. The choice of foundation will not, therefore, be considered as affecting the impact.

\subsubsection{Impact on Birds}

Several studies exist which prove an increase in bird mortality due to the risk of colliding with wind turbines. However, the rate of mortality is variable and relatively low, from 0.01 to 23 mortalities per turbine per year [27]. Other studies, such as the flight of eider duck at Utgrunden off Sweden [1], prove that some birds understand the presence of the wind turbines, even during night time, and accordingly change their route. Therefore, the effects on bird populations can be summarised as: avian mortality through collision, physical change of habitat, and changes in migratory flight paths. The birds with a greater risk of collision are seabirds and migrating passerines. Hence, before installing a wind farm it will be necessary to collect data on bird numbers, distribution and movement in order to predict impacts, because an inappropriate wind farm location can adversely affect wild bird populations [27]. Obviously, the choice of foundation will not affect the impact on birds.

\subsection{Economic Assessment}

The aim of an economic assessment is to study the economic efficiency of building a new offshore wind farm using specific assumptions. For this study a hypothetical wind farm of 30 wind turbines at a distance of $11 \mathrm{~km}$ is assumed. The life cycle period of consideration depends both on the local climatic conditions 
and the quality of the components of the wind turbine. Although it can be analytically derived, a normal service period of 20 years is usually assumed [28].

\subsubsection{Impacts identification}

The positive impacts, which will be referred to as benefits, will account either for an improvement of goods that generate positive utility or a reduction in total price. The negative impacts, which will be referred to as costs, will either be any reduction in the quantity or quality of goods or an increase in total price [29]. The construction of wind farms involves several benefits, including increasing employment and at the same time decreasing fossil fuel consumption. In 2007, the EU wind energy sector directly employed approximately 108,600 people and if indirect employment is included, a total of approximately 154,000 people [30]. For the derivation of the amount of energy produced per year, it is important to introduce the two important concepts of availability and load factor. Wind turbine availability is its capability to operate when the wind is blowing and, for modern European machines, is in the range of $98 \%$ [31] or $95 \%$ as a more conservative approach. The load factor is the ratio of the net amount of electricity generated to the net amount which it could have generated if it were operating at its net output capacity - usually around 30\% [32].

For the theoretical wind farm under consideration, a total output of 411,939 MWh will be assumed based on typical 5.5 MW wind turbines that are adopted by [33], having an approximate cost of $4 \mathrm{M} £$. The cost of electricity generation is selected as $9 \mathrm{p£/kWh}$ based on [34] and [35], while the costs of the support structures is assumed to be $£ 1,500$ per tonne [33], including steel costs, fabrication costs and protection against corrosion. The operational expenditure (OPEX) cost of maintaining an offshore wind farm is in the range of $23 \%$ of the capital expenditure (CAPEX) cost [33], spread over the life cycle. Obviously initial costs will be low because of warranty and final costs will be higher as the farm comes to the end of its life, therefore it will be assumed that costs are spread following a linear increase from year 1 . The costs of the electrical infrastructure correspond to the costs of copper offshore and onshore cables, cable laying, meteorological masts, a Supervisory Control And Data Acquisition (SCADA) system, and the onshore electrical works are based on [33] and [36]. Costs for transportation and installation of the foundations of a wind turbine are based on [33], appropriately 
incorporating potential downtime due to extreme weather conditions. Installation of scour protection and a cost for decommissioning has been included in the study and are based on [33] and [37]. For the total derived costs for each wind turbine, a cost breakdown chart can be formulated and this is presented in Figure 2,

illustrating that the support structures cost represents $15 \%$ of the total costs for the monopile wind farm, while for the jacket wind farm it represents $33 \%$ of the total costs.

\subsubsection{Net Present Value (NPV)}

This parameter will convert the total cost of the service life of the structure to present value. The present value (PV) of a benefit or cost $(\mathrm{X})$ is calculated as follows for $\mathrm{t}$ years and a discount rate of $\mathrm{i}$ :

$$
P V\left(X_{t}\right)=X_{t}\left[(1+i)^{-t}\right]
$$

The further in time a benefit or cost happens, the lower the discount factor $\left[(1+i)^{-t}\right]$ and the present value is. This is justified as there is a level of uncertainty associated with the costs and benefits in the future, hence there is an expressed preference to obtain goods and services now, rather than later [29]. Therefore, the choice of discount rate is of critical importance in determining whether the PV is positive or negative. There is considerable controversy about whether public sector projects should be discounted at a lower rate than private sector projects [38], due to the fact that they can pool risks [39] and can borrow at far lower rates [38].

Within the scope of this study, a public/private partnership will be considered and a $6 \%$ discount rate will be applied. Once all PVs have been calculated, the sum of discounted gains will be checked to see whether it exceeds the sum of discounted losses, accepting projects with an NPV greater than 1. The wind turbines' value for each different support structure configuration and the corresponding NPVs are presented in Table 11.

\begin{tabular}{ll}
\hline & NPV $(\mathfrak{\xi})$ \\
\hline Monopile & $187,682,531$ \\
Tripod & $143,628,070$ \\
Jacket & $105,570,459$ \\
\hline
\end{tabular}

Table 11: Values of different support structures

\subsubsection{Sensitivity Analysis}


This section will investigate the contribution of different parameters in the derived value of NPV. The first analysis will consider the cost of electricity for each offshore wind turbine type. This is an important step because adding wind into the power mix will have a significant influence on the resulting price of electricity. The cost of generating electricity for the monopile wind farm is $5.03 \mathrm{p} / \mathrm{kWh}$, for the tripod wind farm is $5.96 \mathrm{p} / \mathrm{kWh}$, and for the jacket wind farm is $6.77 \mathrm{p} / \mathrm{kWh}$; which are in accordance with the average cost of generating electricity mentioned elsewhere. Therefore, these projects would be profitable even with a fall of 2.2 $\mathrm{p} / \mathrm{kWh}$ of selling price, which according to the Department of Energy and Climate Change (DECC) is unlikely [40].

As mentioned earlier, the discount rate is a crucial parameter in determining whether the PV is positive or negative, so the second analysis was to calculate the Internal Rate of Return (IRR) for each of the three proposed projects. IRR is the interest rate at which the NPV of a project is zero [41]. The results of this analysis are presented in Figure 3, proving that an increase in the discount rate implies a decrease in the NPV. Further it is derived that all projects are likely to receive private investment, since all the IRRs are greater than the cost of capital.

\section{TOPSIS METHOD}

\subsection{Multi-Criteria Decision Analysis}

As mentioned in the introduction and noted throughout this study, the selection of the optimum choice should be based on several attributes; for instance, monopile is economically the best option but it is the worst option for increasing biodiversity. Hence, a Multi-criteria decision analysis (MCDA) method can be employed, capable of providing the best sustainable alternative in this decisionmaking (DM) process which has conflicting attributes. MCDA methods have been widely applied in DM for sustainable energy because of the complexity of socioeconomic and biophysical systems and the multi-dimensionality of the sustainability target [13].

\subsection{Application of the TOPSIS method}

The TOPSIS method is a powerful MCDA method used commonly in optimization problems, and has been chosen from the different types of weighting methods because its basic concept is perfectly suited to this analysis, as [14] 
suggests. Its basic concept is that the best alternative should have the farthest distance from the Negative Ideal Solution (NIS) and the shortest distance from the Positive Ideal Solution (PIS) [42]. This method ensures the realization of objective benchmarking among the options, taking into account both quantitative and qualitative attributes, and follows a sequence of simple steps as presented in

Figure 4.

After the formulation of a design matrix with scoring for every attribute of each option, normalization follows as:

$$
\mathrm{r}_{\mathrm{ij}}=\mathrm{x}_{\mathrm{ij}} / \operatorname{sqrt}\left(\sum_{\mathrm{i}=1 \text { to } \mathrm{m}} \mathrm{x}_{\mathrm{ij}}{ }^{2}\right)
$$

Where:

$\mathrm{x}_{\mathrm{ij}}$ : value of the component that resides in row $\mathrm{i}$ and in column $\mathrm{j}$ of the decision matrix

$\mathrm{i}: 1, \ldots, \mathrm{m}$

$\mathrm{j}: 1, \ldots, \mathrm{n}$

$r_{i j}$ : value of the component that resides in row $i$ and in column $j$ of the normalized matrix

Next, criteria weights $\left(\mathrm{w}_{\mathrm{j}}\right)$ have to be determined to indicate their relative importance and to calculate the weighted normalized values $\left(\mathrm{v}_{\mathrm{ij}}\right)$ through:

$$
\mathrm{v}_{\mathrm{ij}}=\mathrm{w}_{\mathrm{j}} * \mathrm{r}_{\mathrm{ij}}
$$

Having obtained the Weighted Normalized Decision Matrix, the PIS $\left(\mathrm{A}^{+}\right)$and the NIS $\left(\mathrm{A}^{-}\right)$, the ideal solutions are determined as:

$$
\begin{aligned}
A^{+} & =\left\{v_{1}^{+}, \ldots, v_{j}^{+}, \ldots, v_{n}^{+}\right\}=\left\{\left(\max _{j} v_{i j} \mid j=1, \ldots, n\right) \mid i=1, \ldots, m\right\} \\
A^{-} & =\left\{v_{1}^{-}, \ldots, v_{j}^{-}, \ldots, v_{n}^{-}\right\}=\left\{\left(\min _{j} v_{i j} \mid j=1, \ldots, n\right) \mid i=1, \ldots, m\right\}
\end{aligned}
$$

Finally, the ranking of the alternatives will be realized by calculating the relative distance of each solution from the PIS $\left(\mathrm{S}_{\mathrm{i}}^{+}\right)$and to the NIS $\left(\mathrm{S}_{\mathrm{i}}^{-}\right)$, as:

$$
\mathrm{S}_{\mathrm{i}}^{+}=\operatorname{sqrt}\left(\Sigma_{\mathrm{j}=1 \text { to n }}\left(\mathrm{v}_{\mathrm{j}}^{+}-\mathrm{V}_{\mathrm{ij}}\right)^{2}\right), \mathrm{S}_{\mathrm{i}}^{-}=\operatorname{sqrt}\left(\Sigma_{\mathrm{j}=1 \text { to n }}\left(\mathrm{v}_{\mathrm{j}}{ }^{-}-\mathrm{V}_{\mathrm{ij}}\right)^{2}\right)
$$

The relative closeness of each solution to the ideal $\left(\mathrm{C}_{\mathrm{i}}\right)$ will be estimated as follows, and the most favourable will be the one closest to 1 .

$$
\mathrm{C}_{\mathrm{i}}=\mathrm{S}_{\mathrm{i}}^{-} /\left(\mathrm{S}_{\mathrm{i}}^{+}+\mathrm{S}_{\mathrm{i}}^{-}\right)
$$

\subsection{Analysis of Attributes}

Since this study aims to identify the best out of the three most commonly used support structure configurations, there are three alternatives $(\mathrm{m}=3)$, and nine 
criteria have been selected $(n=9)$ for this problem. The selection has been based on the conclusions obtained through the different steps of the study and the recommendations given in [14] of some attributes such as certification, durability and depth compatibility. All these attributes are defined as follows:

- Artificial reefs; this positive criterion, i.e. the higher the better, aims to represent the increment of biodiversity provided by additional substrata for colonization.

- Certification is a positive parameter; it shows if the support structure has already been certified for wind turbines or not. Considering a value of 1 if it has, 0.5 if not but it has already been certified for the same structure used in the offshore oil and gas industry, and 0 if it has not.

- $\mathrm{CO}_{2} \mathrm{e}$ emission is a negative attribute, i.e. the higher emissions reflect the amount of $\mathrm{CO}_{2} \mathrm{e}$ emissions produced for the fabrication of the different support structures.

- Depth compatibility is a negative criterion, representing the compatibility of each support structure with $40 \mathrm{~m}$ water depth. It is scored as 1 if $40 \mathrm{~m}$ depth is within the range of reference depth, 2 if it is within the extended range of reference depth: [minimum reference value*0,75 - maximum reference value*1.25], and 3 if it is not within the extended range of reference depth.

- Maximum displacement is a negative parameter representing the resistance of the structure to lateral displacement as a result of the forces acting on it.

- Durability is a positive criterion, related to the resistance to age-related deterioration. It is marked with values between 1 and 5, obtained from [14], depending on the exposure to corrosion and consequences of fatigue.

- NPV is a positive attribute that shows the economic benefit of selling energy according to the type of offshore wind farm.

- Maximum von Mises Stress is a negative criterion chosen to account for the suitability of the support structures, as it relates to the ductile-brittle transition [43].

- Water turbidity, is a negative attribute aiming to represent disturbance to the seabed caused by the support structure.

Weights influence directly the DM result and are based on the practical engineering expertise of the decision makers; consequently, the more experienced 
the decision makers are, the more objective the result. Although most of the attributes can be expressed in quantitative terms, this is every demanding task. For the present study, the weight vector will be based on the experience of the experts in this field within the Cranfield Offshore Renewable Energy Group. The relative importance of each criterion was determined by a questionnaire based on a Likert scale. With this technique, the responder specifies a level of agreement or disagreement to the concept under study, using one of a number of positions on a five-point Likert scale [44]. In this particular case, the meaning of Likert scale levels was modified, running from 1-Not important to 5-Very Important.

\subsection{Application}

Based on the above analysis, the initial Decision Matrix is defined as:

\begin{tabular}{l|lllllllll|}
\multicolumn{1}{c}{} & 1 & 2 & 3 & 4 & 5 & 6 & 7 & 8 & 9 \\
Monopile & 1100 & 1 & 17191 & 3 & 2.37 & 4 & $187,682,531$ & 177.6 & 1539 \\
Tripod & 3857 & 1 & 35788 & 1 & 3.30 & 5 & $143,628,070$ & 184 & 1069 \\
Jacket & 8787 & 1 & 51833 & 1 & 2.69 & 5 & $105,570,459$ & 223.8 & 2356 \\
\hline
\end{tabular}

The normalized Decision Matrix is derived as:

\begin{tabular}{l|lllllllll|}
\multicolumn{1}{c}{} & 1 & 2 & 3 & 4 & 5 & 6 & 7 & 8 & 9 \\
Monopile & 0.11 & 0.58 & 0.26 & 0.90 & 0.49 & 0.49 & 0.68 & 0.52 & 0.51 \\
Tripod & 0.40 & 0.58 & 0.55 & 0.30 & 0.68 & 0.62 & 0.57 & 0.54 & 0.36 \\
Jacket & 0.91 & 0.58 & 0.79 & 0.30 & 0.55 & 0.62 & 0.47 & 0.66 & 0.78 \\
\hline
\end{tabular}

Results from the averaging of the questionnaires construct the weights vector.

$$
\begin{array}{lllllllll|}
1 & 2 & 3 & 4 & 5 & 6 & 7 & 8 & 9 \\
\cline { 1 - 4 } 0.65 & 0.65 & 0.91 & 0.91 & 0.87 & 1.00 & 1.00 & 0.83 & 0.74 \\
\hline
\end{array}
$$

And the Weighted Normalized Decision Matrix:

\begin{tabular}{l|lllllllll}
\multicolumn{1}{c}{} & 1 & 2 & 3 & 4 & 5 & 6 & 7 & 8 & 9 \\
\cline { 2 - 9 } Monopile & 0.07 & 0.38 & 0.24 & 0.83 & 0.42 & 0.49 & 0.68 & 0.43 & 0.38 \\
Tripod & 0.26 & 0.38 & 0.50 & 0.28 & 0.59 & 0.62 & 0.57 & 0.45 & 0.26 \\
Jacket & 0.59 & 0.38 & 0.72 & 0.28 & 0.48 & 0.62 & 0.47 & 0.54 & 0.58 \\
\hline
\end{tabular}

The derived Positive and Negative Ideal Solutions are derived as:

$$
\begin{array}{llllllllll|}
\text { A+ } & 0.59 & 0.38 & 0.24 & 0.28 & 0.42 & 0.62 & 0.68 & 0.43 & 0.26 \\
\text { A- } & 0.07 & 0.38 & 0.72 & 0.83 & 0.59 & 0.49 & 0.47 & 0.54 & 0.58 \\
\hline
\end{array}
$$


From the calculation of the relative closeness of each support structure to the ideal solution, the tripod was found to provide the best option (0.61) against the monopile (0.44) and the jacket structure (0.55). Further to this analysis, a sensitivity analysis was executed, considering equal weights (1); this study will show the importance of the experienced allocation of weight factors to the derived results. Calculation of the new values of relative closeness will change the total performance of the different options, ranking equally the Tripod and the Jacket structures (0.58) and still keeping the monopile in the third place (0.40).

\section{CONCLUSIONS}

The outcome of this comprehensive study, taking into account additional attributes more than absolute cost, illustrates that for the assumptions considered, the tripod is the best option overall. This seems reasonable because, although the monopile is the most economical option and less harmful to the environment, the tripod suffers less from wave-resonance than the monopile. Since the obtained results in the different sections provide a consistent end result, it can be concluded that the methodology that has been followed and is proposed in this paper is appropriate. This considers not only the methodology used for soil-structure interaction, environmental and operational loads, but also implementation of the TOPSIS method in order to provide an objective methodology for benchmarking the different support structure options, taking into account engineering, economic and environmental criteria.

A sensitivity analysis, with a more analytical consideration of the weight factors employed using the TOPSIS method, has demonstrated the effect of each of the different attributes on the total scoring, increasing the level of objectiveness of the classification of the different options.

Future work, following this study, should consider examination of the effect of the water depth and the environmental conditions' consideration to the decision making process towards the selection of the most suitable configuration as well as the performance of other attributes. Lastly, the quantification of qualitative attributes on the basis of a reference unit would contribute towards a more informed decision making process.

\section{REFERENCES}


[1] Nikolaos, N., Deep water offshore wind technologies, University of Strathclyde, Glasgow, 2004.

[2] U.S. Department of Energy, Historic Wind Development in New England: The Age of PURPA Spawns the "Wind Farm", [Online] 2010 (Accessed: 13/06/2010), http://www.windpoweringamerica.gov/ne_history_windfarms.asp. [3] RenewableUK, Onshore Wind, [Online] 2010 (Accessed: 04/07/2010), http://www.bwea.com/onshore/index.html.

[4] World of wind energy, What is Wind turbine sitting?, [Online] 2010 (Accessed: 03/09/2010), http://www.worldofwindenergy.com/vbnews.php?do=viewarticle\&artid=31\&title =wind-energy.

[5] Wind Energy Update, Offshore wind piques investor interest, [Online] 2010 (Accessed: 26/05/2010), http://social.windenergyupdate.com/qa/offshore-windpiques-investor-interest.

[6] BERR, Department for Business Enterprise \& Regulatory Reform, Review of reef effects of offshore wind farm structures and potential for enhancement and mitigation, [Online] 2008 (Accessed: 03/09/2010), http://webarchive.nationalarchives.gov.uk/+/http://www.berr.gov.uk/files/file4352 8.pdf.

[7] Pepper, L., Monitoring \& Evaluation of Blyth Offshore Wind Farm, [Online] 2001 (Accessed: 01/09/2010),

http://webarchive.nationalarchives.gov.uk/+/http://www.berr.gov.uk/files/file2036 4.pdf.

[8] RenewableUK, Offshore wind energy reaches 1 GW, [Online] 2010 (Accessed: 28/08/2010), http://www.bwea.com/media/news/articles/pr20100423.html.

[9] Energy Efficiency news, UK becomes world leader in offshore wind, [Online] 2008 (Accessed: 02/09/2010), http://www.energyefficiencynews.com/i/1456/.

10. European Commission. Renewable Energy. What do we want to achieve? [Online] 2010. (Accessed: 25/08/2010). http://ec.europa.eu/energy/renewables/index_en.htm. 
[11] European Union Committee, The EU's Target for Renewable Energy: 20\% by 2020, [Online] 2008 (Accessed: 25/10/2010), http://www.publications.parliament.uk/pa/ld200708/ldselect/ldeucom/175/175.pdf [12] Sustainable Development Commission, Wind Power in the UK, [Online] 2005 (Accessed: 26/08/2010), http://www.sd-commission.org.uk/pages/windpower-in-the-uk.html.

[13] Wang, J., Jing, Y., Zhang, C., Zhao, J., Review on multi-criteria decision analysis aid in sustainable energy decision-making. Baoding, Renewable and Sustainable Energy Reviews - Elsevier, 2009.

[14] Kolios, A., Collu, M., Chahardehi, A., Brennan, F. P. and Patel, M. H., A Multi-Criteria Decision Making Method to Compare Support Structures for Offshore Wind Turbines. Offshore, Process \& Engineering Department, School of Engineering, Cranfield University, Bedforshire, European Wind Energy Conference and Exhibition (EWEC), 2010.

[15] Veritas, Det Norske, DNV J101.

[16] CEN, Eurocode 3.

[17] Jonkman, J., Butterfield, S., Musial, W., Scott, G., Definition of a 5-MW Reference Wind Turbine for Offshore System Development, National Renewable Energy Laboratory, Colorado, 2009.

[18] Bruns, E., Andersson, A. and Thor, S-E., Environmental issues of offshore wind farms, [Online] 2002 (Accessed: 21/08/2010),

http://www.ieawind.org/Task_11/TopicalExpert/Summary_40_Offshore.pdf. [19] Punt, M. J., Groeneveld, R. A., van Ierland, E. C., Stel, J. H., Spatial planning of offshore wind farms: A windfall to marine environmental protection?, Ecological Economics - Elsevier, Netherlands, 2009. 69 (2009) 93-103.

[20] Snyder, B. and Kaise, M. J., Ecological and economic cost-benefit analysis of offshore wind energy, Renewable Energy - Elsevier, Baton Rouge, 2008. [21] Pertsova, C. C., Ecological Economics Research Trends, Nova Science Publishers, New York ,2007.

[22] Schleisner, L., Life cycle assessment of a wind farm and related externalities, Pergamon, 2000. pp. 279-288. Vol. 20.

[23] Dean, W. D., Wind Turbine Mechanical Vibrations: Potential Environmental Threat, [Online] 2007 (Accessed: 21/08/2010), http://www.sosmoray.org.uk/Dixie_dean.pdf. 
[24] Aqua-Fact International Services Ltd., Sceirde offshore wind farm Environmental Impact statement, [Online] 2008 (Accessed: 21/08/2010), http://www.fsteo.com/Non-Technical\%20Summary.pdf.

[25] Hiscock, K., Tyler-Walters, H. and Jones, H., High Level Environmental Screening Study for Offshore Wind Farm Developments - Marine Habitats and Species Project, [Online] 2002 (Accessed: 21/08/2010), http://citeseerx.ist.psu.edu/viewdoc/download?doi=10.1.1.113.1621\&rep=rep1\&t ype $=$ pdf.

[26] Gill, A. B., Gloyne-Phillips, I., Neal, K. J., Kimber, J. A., The potential effects of electromagnetic fields generated by sub-sea power cables associated with offshore wind farm developments on electrically and magnetically sensitive marine organisms - a review, [Online] 2005 (Accessed: 21/08/2010), http://www.offshorewindfarms.co.uk/Assets/1351_emf_phase_one_half_report.pdf. [27] Drewitt, A. L. and Langston, R. H. W., Assessing the impacts of wind farms on birds, 2006, pp. 29-42. Vol. 148.

[28] DNV, Det Norske Veritas, Design of offshore wind turbine structures, Offshore Standard DNV-OS-J101, 2007.

[29] Hanley, N. and Spash, C. L., Cost-Benefit Analysis and the Environment, Edward Elgar Publishing Inc., Cheltenham, 2003, pp. 53-73, 261-273.

[30] Blanco, I. and Kjaer, C., Wind at Work, [Online] 2009 (Accessed: 14/08/2010), http://www.ewea.org/fileadmin/ewea_documents/documents/publications/Wind_a t_work_FINAL.pdf.

[31] BWEA, The British Wind Energy Association, Wind Turbine Technology, [Online] 2005 (Accessed: 18/08/2010), http://www.bwea.com/pdf/briefings/technology05_small.pdf.

[32] RenewableUK, Can We Rely on the Wind?, [Online] 2010 (Accessed: 18/08/2010), http://www.bwea.com/energy/rely.html.

[33] ODE Ltd, Offshore Design Engineering Limited, Study of the costs of offshore wind generation, [Online] 2007 (Accessed: 12/07/10), http://www.odeltd.co.uk/renewables/dti\%20Costs\%20of\%20Offshore\%20Wind\%20Generation\% 20by\%20ode.pdf. 
[34] NEP, Nottingham Energy Partnership, Energy Costs Comparison, [Online] (Accessed: 18/08/2010), http://www.nottenergy.com/energy-costscomparison3.

[35] The Royal Academy of Engineering, Costs of Generating Electricity, [Online] (Accessed: 17/08/2010), http://www.raeng.org.uk/news/publications/list/reports/Cost_Generation_Comme ntary.pdf.

[36] Morgan, C. A., Snodin, H. M. and Scott, N. C., Garrad Hassan, OFFSHORE WIND Economies of scale, engineering resource and load factors, [Online] 2003 (Accessed: 02/08/2010),

http://www.decc.gov.uk/assets/decc/what\%20we\%20do/uk\%20energy\%20supply/ energy\%20mix/renewable\%20energy/policy/file22067.pdf.

[37] Iberdrola Renewables, Buffalo Ridge II Wind Farm Decommissioning Report, [Online] (Accessed: 15/08/2010), http://puc.sd.gov/commission/dockets/electric/2008/el08-031/Appendix\%20h.pdf. [38] Grout, P. A., Public and Private Sector Discount Rates in Public-Private Partnerships, [Online] 2002 (Accessed: 03/11/2010), http://www.bristol.ac.uk/cmpo/publications/papers/2003/wp59.pdf.

[39] Arrow, K. and Lind, R. C., Uncertainty and the Evaluation of Public Investment Decisions, American Economic Review, 1970, pp. 364-378. Vol. 60. [40] DECC, Department of Energy and Climate Change, Cost of and financial support for offshore wind, [Online] 2009 (Accessed: 03/09/2010), http://webarchive.nationalarchives.gov.uk/+/http://www.berr.gov.uk/files/file5114 2.pdf.

[41] Black, J., Hashimzade, N. and Myles, G., A Dictionary of Economics, Oxford University Press, Oxford, 2009.

[42] Hwang, C. L. and Yoon, K., Multiple attribute decision-makingmethods and application: a state-of-the-art survey, Springer-Verlag, New York, 1981.

[43] n/a., ANTEC'96: Plastics-Racing into the Future, Society of Plastics Engineers, 1996. Vol. 3: Special areas.

[44] McDaniel, Carl D. and Gates, Roger H., Marketing research essentials, South-Western College Publishing, U.S.A., 1998, pp. 247-248. 


\section{Figure 1: Monopile, Tripod and Jacket Support Structures.}
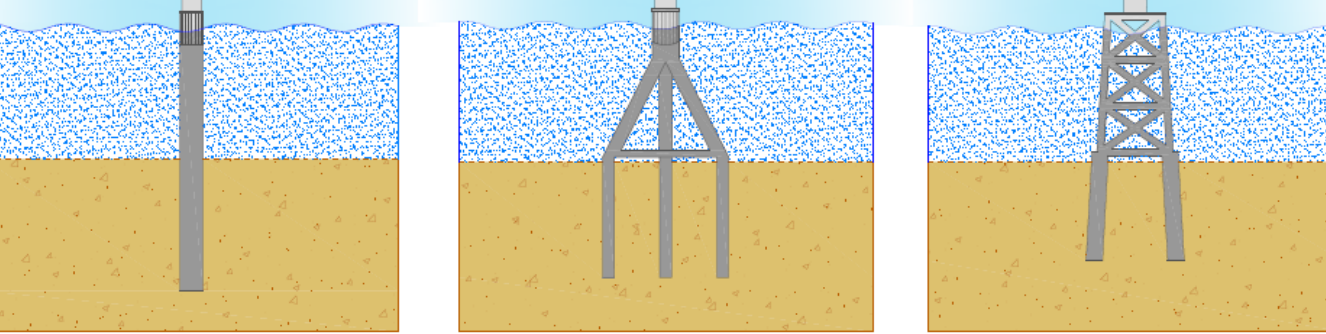


\section{Figure2: Cost Breakdown of different configurations.}

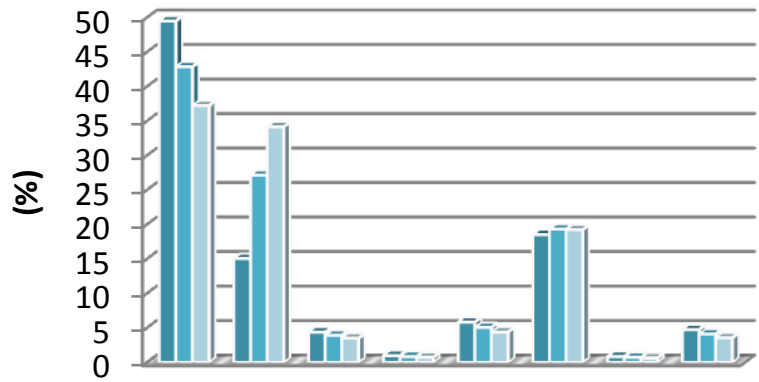

- Monopile Wind Farm

- Tripod Wind Farm

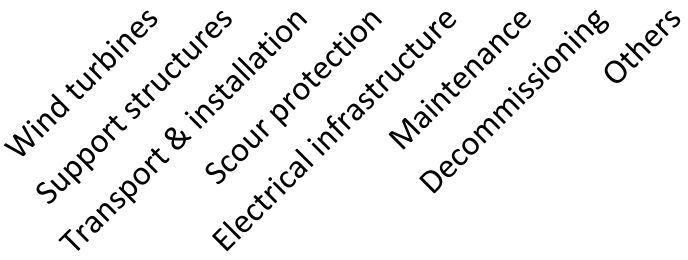

Jacket Wind Farm 
Figure 3: IRRs for proposed farms.

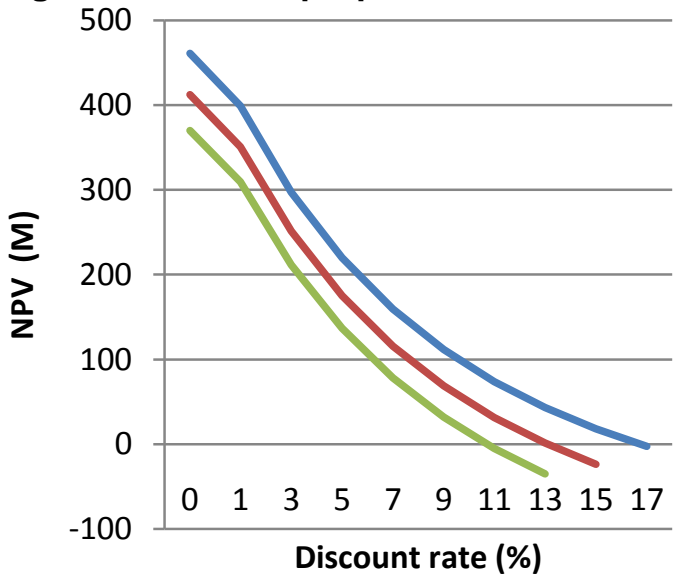

Monopile Wind Farm Tripod Wind Farm Jacket Wind Farm 
Figure 4: TOPSIS Method flowchart.
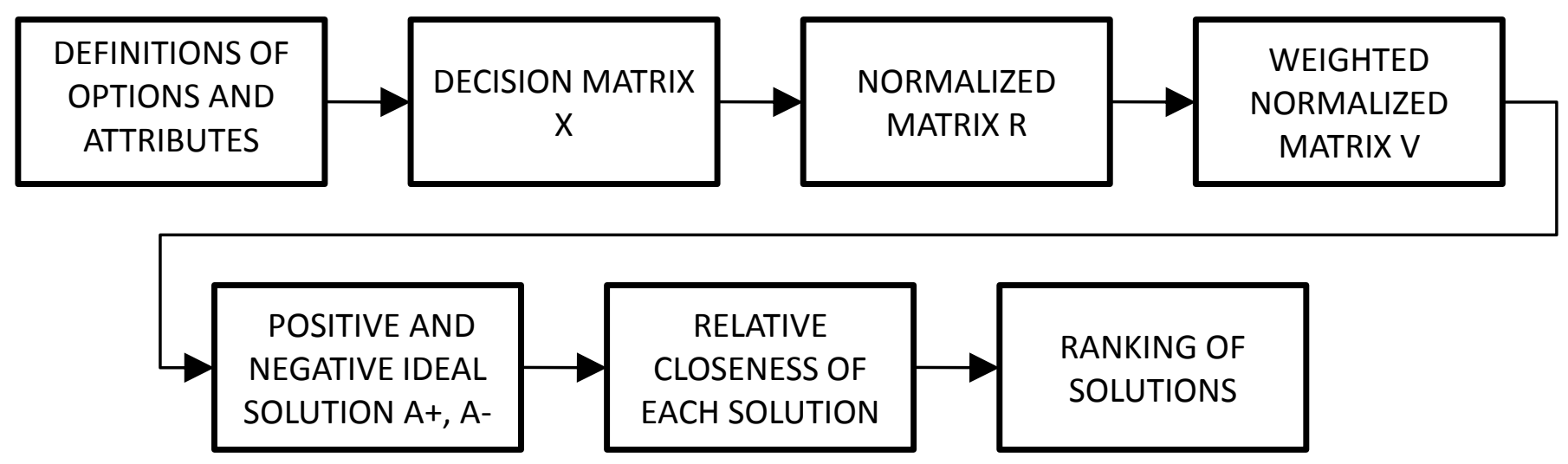